\title{
Interferon-alpha is a predisposing risk factor for carbamazepine-induced hyponatremia:A case of syndrome of inappropriate antidiuresis caused by interferon-alpha therapy
}

\author{
Midori Tanaka \\ Kyuzi Kamoi \\ Toru Takahashi \\ Department of Internal Medicine, \\ Nagaoka Red Cross Hospital, \\ Nagaoka, Niigata, Japan
}

\begin{abstract}
A 31-year-old man had been treated with carbamazepine (CBZ) for 6 years and warfarin with bucolome for 2 years before developing hyponatremia 7 days after an injection of interferon-alpha $2 \mathrm{~b}$ and starting oral ribavirin for chronic hepatitis $\mathrm{C}$ virus infection. Despite the hyponatremia, urinary osmolality exceeded plasma osmolality, and urinary excretion volume decreased markedly after water loading. Restriction of water intake and administration of dimethylchlortetracycline improved the hyponatremia, and lithium therapy maintained the normonatremia for one year. The hyponatremia recovered 6 months after the interferonalpha $2 \mathrm{~b}$ therapy was completely stopped. In the present case, the syndrome of inappropriate antidiuresis may have been caused by the effect of interferon-alpha $2 \mathrm{~b}$ on the renal distal tubules that had been sensitized by CBZ. Patients on CBZ therapy should be carefully observed for the development of hyponatremia when they are started on interferon-alpha $2 b$ injections.
\end{abstract}

Keywords: hyponatremia, carbamazepine, interferon-alpha therapy, other drugs

\section{Introduction}

Carbamazepine (CBZ), a commonly prescribed medication in psychiatry and neurology, produces side effects with an incidence ranging from $33 \%-50 \%$. CBZ-induced hyponatremia is a well-described side effect, and numerous studies have shown that age, hyponatremia dosage/level, and polypharmacy are predisposing risk factors for CBZ-induced hyponatremia (Gandelman 1994). Polypharmacy is a particularly important risk factor (Kuz and Manssourian 2005).

We report a case of the syndrome of inappropriate antidiuresis (SIAD) caused by interferon-alpha therapy in a patient with chronic hepatitis $\mathrm{C}$ virus infection, who had been treated with CBZ for a long time.

\section{Case report}

Twelve days after the start of interferon-alpha and ribavirin therapy, a 31-year-old man was admitted for investigation of hyponatremia. The patient had been given a large blood transfusion and had undergone bone marrow transplantation for acute leukemia at 17 years of age, following which he developed chronic hepatitis $\mathrm{C}$ virus infection. At the age of 25 years, CBZ ( $400 \mathrm{mg} /$ day) treatment was begun for temporal lobe epilepsy, and, 1 year later, the CBZ dose was increased to $800 \mathrm{mg} /$ day. At the age of 29 years, the patient developed deep venous thrombosis of the right leg and was treated with catheterdirected thrombolysis using an intravenous catheter filter; he was then placed on warfarin potassium (1.5 mg/day) and bucolome (300 mg/day) orally. On August 11, 2005, the patient was started on interferon-alpha $2 \mathrm{~b}$ injections (100 $\mu \mathrm{g} /$ week) subcutaneously and 
ribavirin ( $800 \mathrm{mg} /$ day) orally for worsening liver function; GOT (glutamic-oxaloacetic transaminase) was 34 IU/l, GPT (glutamic-pyruvic transaminase) was $63 \mathrm{IU} / 1$, and hepatitis C virus-RNA titer was high $(700 \mathrm{KIU} / \mathrm{ml})$. Before interferon-alpha and ribavirin therapy were started, blood electrolytes, including serum sodium level, had been consistently normal (Figure 1). The patient was not anemic, and the C-reactive protein level was normal. The patient complained of fatigue 7 days after beginning interferon-alpha $2 \mathrm{~b}$ and ribavirin therapy; laboratory testing showed that he had hyponatremia (Figure 1).

The patient was $175 \mathrm{~cm}$ tall and weighed $71 \mathrm{~kg}$. Temperature was normal $\left(36.2^{\circ} \mathrm{C}\right)$, and the blood pressure $(94 / 58 \mathrm{mmHg})$ and the pulse rate $(80 / \mathrm{min})$ were normal in the recumbent position. Examination of the palpebral conjunctiva indicated anemia. No signs of edema, dehydration, or abnormal pigmentation were present. The patient was fully conscious. Laboratory findings showed anemia and a high C-reactive protein level. Other tests, including interleukin levels, were within normal limits. A plain chest X-ray film was normal. Computed tomography body scans and electrocardiograms were normal. The intensity of the posterior pituitary gland was normal on T1-weighted magnetic resonance imaging.

Despite a hypo-osmotic hyponatremia, the patient's urinary sodium concentration was higher than $20 \mathrm{mEq} / \mathrm{l}$, and urine osmolality was also higher than his blood osmolality
(Table 1). The serum uric acid was low. Thyroid, adrenal, and renal functions were normal, and plasma renin, aldosterone, and atrial natriuretic peptide (ANP) concentrations were normal (Table 1).

The CBZ, warfarin potassium, and bucolome could not be discontinued because they were all essential; in particular, of all the other antiepileptic regimens, only CBZ was effective for treating his epilepsy. Furthermore, the interferon-alpha $2 \mathrm{~b}$ and ribavirin treatments were considered essential to treat his chronic hepatitis $\mathrm{C}$ virus infection for one year.

The arginine vasopressin (AVP) level and the plasma osmolality were normalized to $6.1 \mathrm{pg} / \mathrm{ml}$ and $291 \mathrm{mosmol} / \mathrm{kg}$, respectively, by administration of dimethylchlortetracycline (DMC) $(900 \mathrm{mg} /$ day) and restriction of water intake $(20 \mathrm{ml} / \mathrm{kg}$ body weight) (Figure 1). Lithium (400 mg/day) therapy for one year resulted in normonatremia, with a plasma AVP concentration of less than $0.5 \mathrm{pg} / \mathrm{ml}$ (Figure 1); this effectively prevented the development of hyponatremia. Administration of lithium with restriction of water intake was discontinued one year later. Subsequently, the hyponatremia worsened during interferon-alpha $2 b$ therapy (Figure 1). Two weeks later, the interferon-alpha $2 \mathrm{~b}$ therapy was also stopped, and the hyponatremia completely recovered 6 months later while CBZ, warfarin potassium, and bucolome were continued (Figure 1). One year later, the blood sodium and AVP concentrations were $137 \mathrm{mEq} / \mathrm{l}$ and $0.7 \mathrm{pg} / \mathrm{ml}$, respectively.

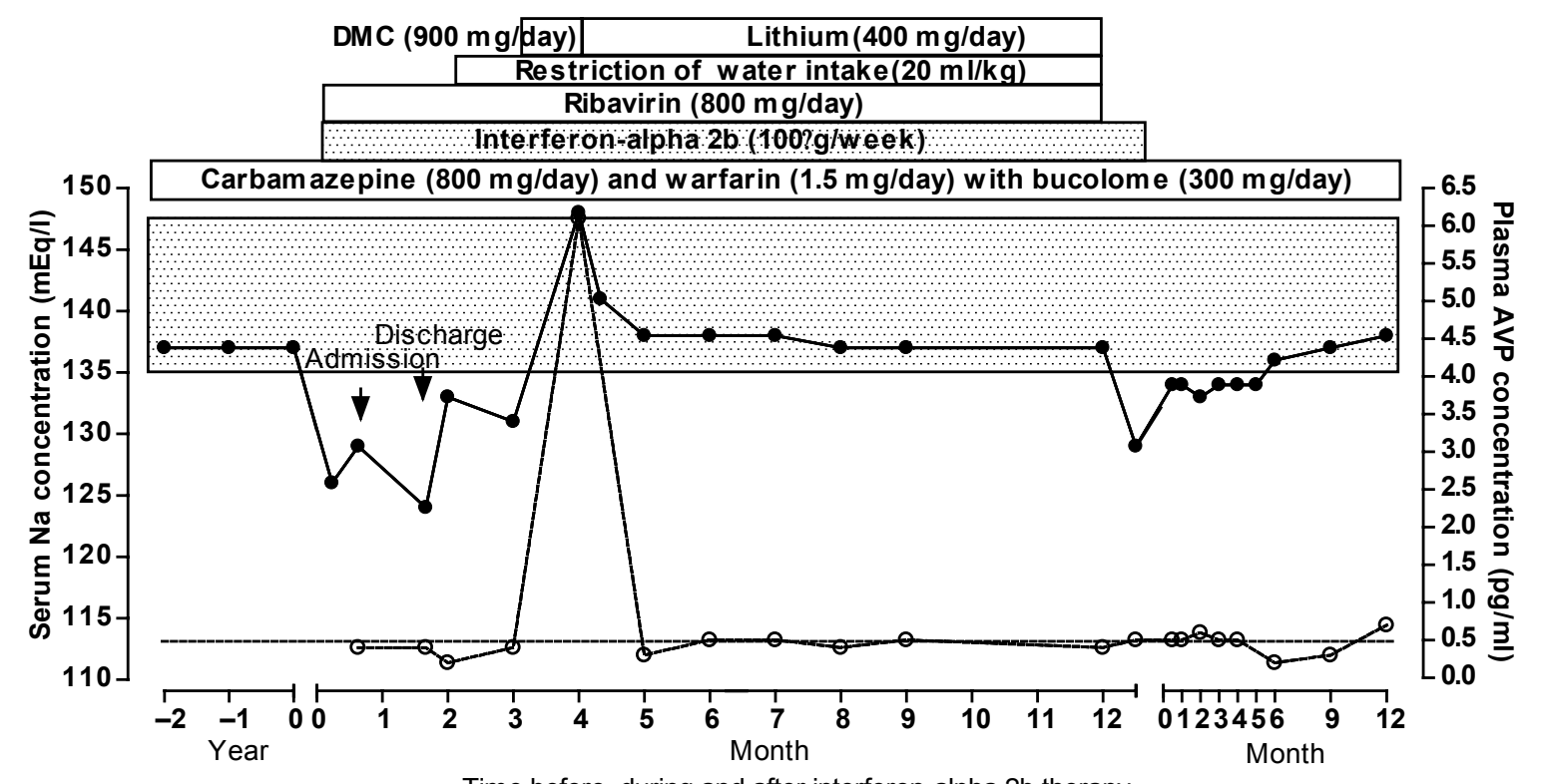

Time before, during and after interferon-alpha $2 b$ therapy

Figure I Changes in serum sodium (Na) concentration $(\bullet-\bullet)$ and plasma vasopressin (AVP) concentration $(\circ \cdots \circ)$ before and during interferon-alpha $2 b$ therapy during water intake restriction with dimethylchlortetracycline (DMC) or lithium, and after their discontinuation. The carbamazepine, warfarin potassium, and bucolome had been administered for more than 2 years before hyponatremia developed and had been continued afterwards. The stippled bar represents the normal serum Na concentration range, and the dotted line represents the lower limit of the normal AVP concentration range. 
Table I Endocrinological analysis during the week after admission

\begin{tabular}{llll}
\hline & Blood & & Urine \\
\hline Sodium & $124 \mathrm{mEq} / \mathrm{l}$ & & $95 \mathrm{mEq} / \mathrm{l}$ \\
Osmolality & $260 \mathrm{mosmol} / \mathrm{kg}$ & & $710 \mathrm{mosmol} / \mathrm{kg}$ \\
& Blood & Renin & $4.3 \mathrm{pg} / \mathrm{ml}(2.5-21)$ \\
Vasopressin & $0.4 \mathrm{pg} / \mathrm{ml}(0.5-3.1)$ & ANP & $40.5 \mathrm{pg} / \mathrm{ml}(0-43)$ \\
Aldosterone & $65 \mathrm{pg} / \mathrm{ml}(45-106)$ & Antithyroglobulin antibody & $<0.3 \mathrm{U} / \mathrm{ml}(<0.3)$ \\
TSH & $2.1 \mu \mathrm{U} / \mathrm{ml}(0.30-4.30)$ & Antiperoxidase antibody & $<0.1 \mathrm{U} / \mathrm{ml}(<0.1)$ \\
Free $\mathrm{T}_{3}$ & $2.39 \mathrm{pg} / \mathrm{ml}(2.00-4.90)$ & TSH receptor antibody & $<1.0 \mathrm{IU} / \mathrm{l}(<\mathrm{I.0})$ \\
Free $\mathrm{T}_{4}$ & $0.91 \mathrm{ng} / \mathrm{dl}(0.70-1.80)$ & ACTH* & $10.5 \mathrm{pg} / \mathrm{ml}(4.4-48)$ \\
Cortisol* & $17 \mu g / \mathrm{dl}(4-19)$ & Interleukin-6 & $1.92 \mathrm{pg} / \mathrm{ml}(0.22-4.62)$ \\
Interleukin-I $\beta$ & $<0.125 \mathrm{pg} / \mathrm{ml}(<0.125)$ & &
\end{tabular}

Notes: *Sampled at 8 AM. ANP; atrial natriuretic hormone.

The basal AVP concentration relative to plasma osmolality was below the normal range in healthy subjects (Figure 1), and it was suppressed by $50 \%$ with water loading performed 19 days after starting interferon-alpha $2 \mathrm{~b}$ injections (Figure 2). Plasma ANP levels decreased after water loading (Figure 2). One year after discontinuing interferon-alpha $2 b$ therapy, while still taking CBZ, warfarin potassium, and bucolome, a second water-loading test showed that the minimum plasma sodium and osmolality values obtained 4 hours after water loading were higher than those obtained at the time of the first water-loading test, but they were still lower than those in healthy subjects (Figure 2), and they were accompanied with a nonsuppressive sodium concentration and osmolality in the urine. The cumulative urine volume excretion increased more than during the first water-loading test, but it was still lower than in healthy subjects (Figure 2). The baseline plasma AVP level was higher than it had been during the first water-loading test, and it was not suppressed after water loading, while the plasma ANP levels at baseline and during water loading were normalized (Figure 2).

\section{Discussion}

CBZ-induced hyponatremia is uncommon in patients treated with CBZ alone (Gandelman 1994). Although the predisposing risk factors include age, CBZ dosage/level, and polypharmacy, polypharmacy is a particularly important risk factor (Kuz and Manssourian 2005). The present patient developed hyponatremia after receiving interferon-alpha $2 \mathrm{~b}$ therapy while on CBZ treatment, and the hyponatremia recovered completely when the interferon-alpha $2 \mathrm{~b}$ therapy was stopped. The laboratory data indicate that the hyponatremia was not due to adrenal insufficiency, such as Sheehan's syndrome, with interferon treatment (Mabe et al 1997), but might have been due to abnormal antidiuresis (Zerbe et al 1980).
The abnormal antidiuresis was confirmed by the marked decrease in the cumulative urine excretion for 4 hours after water loading. Though it has generally been considered dangerous to perform the water-loading test in patients with hyponatremia, in the present case, no serious adverse events occurred during the water-loading test.

There have been many reports of hyponatremia in patients treated with interferon (Jones et al 1983; Bennet et al 1986; Lei et al 1995; Berghmans 1996; Bjorck and Samuelsson 1996). However, the mechanism is unclear.

In healthy subjects, plasma ANP concentration increases as plasma volume increases (Kamoi et al 1988). Although patients with SIAD show various changes (Kamoi et al 1987; Kamoi 1997), in the present case, SIAD was suppressed by the increase in plasma volume induced by water loading. Therefore, ANP secretion did not cause the SIAD. Another possible cause is a neoplasm (Kamoi et al 1987). However, in the present patient, there was no evidence of a neoplasm. The patient's high C-reactive protein level may have caused SIAD. Although such hyponatremia may be caused by increased interleukin- $1 \beta$ or -6 levels (Mastorakos et al 1994; Chubachi et al 1995), blood levels of these cytokines were not elevated in the present patient. Various autoimmune diseases induced by interferon-alpha therapy (Conrad 2003) may cause SIAD due to the presence of a $\mathrm{V} 2$ receptor-stimulating antibody, such as the thyrotropin-stimulating hormone receptorstimulating antibody found in Grave's disease. Alternately, interferon alpha may cause constitutive activation of the V2 receptor with polymorphism, as shown when a mutation of the V2 receptor causes an SIADH-like clinical picture (Feldman et al 2005). The possibilities are unlikely because there are no reports in the literature. 

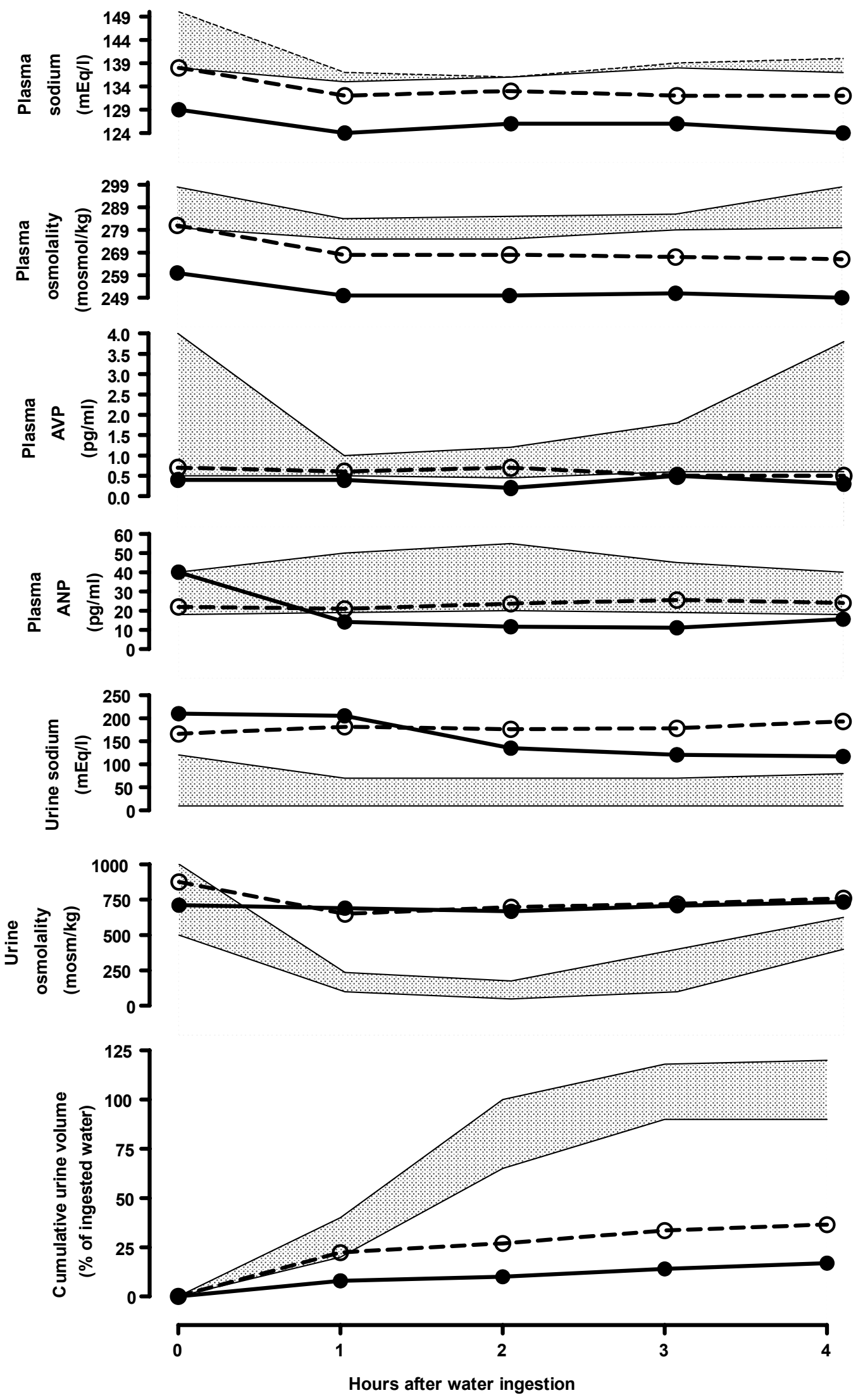

Figure 2 Changes in blood and urine sodium concentrations and osmolality, and in plasma atrial natriuretic hormone (ANP) and vasopressin (AVP) levels, and cumulative urine volume with water loading $(20 \mathrm{ml} / \mathrm{kg}) 19$ days after beginning interferon-alpha $2 \mathrm{~b}$ therapy while continuing carbamazepine, warfarin, and bucolome, $(\bullet-\bullet)$ and the corresponding changes $(\circ \cdots \circ)$ during repeated water loading one year after discontinuation of interferon-alpha $2 b$ therapy. Each stippled area represents the normal range. 
The most likely cause of the hyponatremia in the present case was that interferon therapy may have reinforced a direct or indirect pharmacological effect of other drugs on the renal tubules. To the best of our knowledge, hyponatremia caused by administration of warfarin with bucolome or ribavirin alone has not been reported in the literature. Also, interferon therapy alone has not been demonstrated to cause SIAD. Most patients appear to develop SIAD in combination with other drugs (Jones et al 1983; Bennet et al 1986; Lei et al 1995; Berghmans 1996; Bjorck and Samuelsson 1996). In fact, CBZ is known to sensitize the renal distal tubules (Meinders et al 1974; Wales 1975; Stephens et al 1978) or to cause inappropriate secretion of AVP (Soelberg Sørensen and Hammer 1984), thus, CBZ could have caused the abnormal antidiuresis in the present case. In addition, hyponatremia has been shown to improve following withdrawal of CBZ (Inamura et al 1999). However, in the present case, CBZ could not be stopped because it was essential. In addition, the possibility that $\mathrm{CBZ}$ causes hyponatremia is supported by the observation that lithium therapy and DMC are useful to treat it (Vieweg et al 1987), although lithium and CBZ in combination have been reported to be neurotoxic. It should be emphasized that prescribing these medications together should be done with caution. In the present case, CBZ therapy alone did not cause hyponatremia, and the combination of $\mathrm{CNZ}$ and interferon therapy may have caused the hyponatremia. This finding supports the hypothesis that interferon-alpha $2 \mathrm{~b}$ is a predisposing risk factor for CBZ-induced hyponatremia. Although the factors associated with an increased risk for CBZ-induced hyponatremia are less well understood (Kuz and Manssourian 2005), interferon therapy should be considered a predisposing risk factor. Although CBZ levels were not drawn before and after the introduction of interferon alpha in any of the reported cases, CBZ blood levels would have helped establish CBZ as a predisposing risk factor.

In conclusion, we report the case of a young man who developed SIAD following interferon-alpha $2 b$ therapy for chronic hepatitis $C$ virus. The SIAD may have been caused by sensitizing substances that may have enhanced the direct or indirect pharmacological effects of interferon-alpha on the renal distal tubules. Patients on CBZ therapy should be observed carefully for the development of hyponatremia when they are started on interferon-alpha $2 b$ therapy.

\section{Disclosure}

This work was presented in part at the 16th Meeting of The Vasopressin Institute on January 8, 2006. The authors report no conflicts of interest.

\section{References}

Bennett CL, Vogelzang NJ, Ratain MJ, et al. 1986. Hyponatremia and other toxic effects during a phase I trial of recombinant human gamma interferon and vinblastine. Cancer Treat Rep, 70:1081-4.

Berghmans T. 1996. Hyponatremia related to medical anticancer treatment. Support Care Cancer, 4:341-50.

Bjorck E, Samuelsson L. 1996. Syndrome of inappropriate secretion of antidiuretic hormone (SIADH) after treatment with cyclophosphamide, alpha-interferon and betamethasone in a patient with multiple myeloma. Eur J Haematol, 56:323-5.

Chubachi A, Miura I, Hatano Y, et al. 1995. Syndrome of inappropriate secretion of antidiuretic hormone in patients with lymphoma- associated hemophagocytic syndrome. Ann Hematol, 70:53-5.

Conrad B. 2003. Potential mechanisms of interferon-alpha induced autoimmunity. Autoimmunity, 36:519-23.

Feldman BJ, Rosenthal SM, Vargas GA, et al. 2005. Nephrogenic syndrome of inappropriate antidiuresis. N Engl J Med, 352:1884-90.

Gandelman MS. 1994. Review of carbamazepine-induced hyponatremia. Prog Neuropsychopharmacol Biol Psychiatry, 18:1211-3.

Inamura T, Kuba H, Morioka T, et al. 1999. Carbamazepine induced hyponatremia. No Shinkei Geka. 27:85-7.

Jones DH, Bleehen NM, Slater AJ, et al. 1983. Human lymphoblast interferon in the treatment of small cell lung cancer. Br J Cancer, 47:361-6.

Kamoi K, Ebe T, Hasegawa A, et al. 1987. Hyponatremia in small cell lung cancer. Mechanism not involving inappropriate ADH secretion. Cancer, 60:1089-93.

Kamoi K, Sato F, Arai O, et al. 1988. Effects of plasma volume and osmolality on secretion of atrial natriuretic peptide and vasopressin in man. Acta Endocrinol (Copenh), 118:51-8.

Kamoi K. 1997. Syndrome of inappropriate antidiuresis without involving inappropriate secretion of vasopressin in elderly women: effect of intravenous administration of the nonpeptide vasopressin V2 receptor antagonist OPC-31260. Nephron, 76:111-5.

Kuz GM, Manssourian A. 2005. Carbamazepine-induced hyponatremia: Assessment of risk factors. Ann Pharmacother, 39:1943-6.

Lei KIK, Wickham NW, Johnson PJ. 1995. Severe hyponatremia due to syndrome of inappropriate secretion of antidiuretic hormone in a patient receiving interferon-alpha for chronic myeloid leukemia. Am J Hematol, 49:100.

Mabe K, Shinzawa H, Yamatani K, et al. 1997. Case report: interferon induced coma in Sheehan's syndrome. J Gastroenterol Hepatol, 12:551-3.

Mastorakos G, Weber JS, Magiakou MA, et al. 1994. Hypothalamicpituitary-adrenal axis activation and stimulation of systemic vasopressin secretion by recombinant interleukin- 6 in humans: potential implications for the syndrome of inappropriate vasopressin secretion. $J$ Clin Endocrinol Metab, 79:932-3.

Meinders AE, Cejka V, Robertson GL. 1974. The antidiuretic action of carbamazepine in man. Clin Sci Mol Med, 47:289-99.

Soelberg Sørensen P, Hammer M. 1984. Effects of long-term carbamazepine treatment on water metabolism and plasma vasopressin concentration. Eur J Clin Pharmacol, 26:719-22.

Stephens WP, Coe JY, Baylis PH. 1978. Plasma arginine vasopressin concentrations and antidiuretic action of carbamazepine. $\mathrm{Br}$ Med $\mathrm{J}$, 3:1445-7.

Vieweg V, Glick JL, Herring S, et al. 1987. Absence of carbamazepineinduced hyponatremia among patients also given lithium. Am J Psychiatry, 144:943-7.

Wales JK. 1975. Treatment of diabetes insipidus with carbamazepine. Lancet, 2:948-51.

Zerbe RL, Strope L, Robertson GL. 1980.Vasopressin function in the syndrome of inappropriate antidiuresis. Ann Rev Med, 31:315-27. 
